\title{
Optimum Design of Three Layer Compound Cylinder
}

\author{
Tapan Majumder ${ }^{1}$, Susenjit Sarkar ${ }^{2}$, Samar Ch.Mondal ${ }^{3}$, Dulal Krishna \\ $\mathrm{Mandal}^{4}$ \\ 1,2,3,4 (Department of Mechanical Engg., Jadavpur University, Kolkata - 7000 032, India)
}

\begin{abstract}
The main objective of this paper is to optimize design of three layer compound cylinder for a specific internal pressure. Optimally designed three layer cylinder has equal maximum hoop stresses at the inner surfaces in each cylinder. Here three important parameters are considered for optimization - interface diameter, interference and outside diameter, keeping other parameters such as material, internal diameter and internal pressure, etc. are constant. In order to shrink-fit successive shells upon one another, the outer shell must be expanded by heating; it may then be slipped over the inner shell or shells and allowed to cool. So a preheat temperature necessary to provide the required thermal expansions. This paper introduces the methodology for optimum design of shrink fitted three-layer compound cylinder based on maximum tensile stress. Then the analytical results of optimum design calculated are validated with Finite Element Analysis in ANSYS WORKBENCH environment.
\end{abstract}

Keywords: Compound cylinder, Finite element analysis, Maximum tensile stress, Optimum design, Shrink fit.

\section{Introduction}

The pressure vessels are used to store fluids under pressure. Pressure vessels find wide applications in thermal and nuclear power plants, process and chemical industries, in space and ocean depths, and in water, steam, gas and air supply system in industries. The material of a pressure vessel may be brittle such as cast iron, or ductile such as mild steel.

With increasing demands from industrial processes for higher operating pressures and higher temperature, new technologies have been developed to handle the present day specialized requirements. Multilayer Pressure Vessels have extended the art of pressure vessel construction and presented the process designer with a reliable piece of equipment useful in a wide range of operating conditions for the problems generated by the storage of hydrogen and hydrogenation processes.

Patil has introduced optimum design of two layer compound cylinder and optimized intermediate, outer diameter and shrinkage tolerance to get minimum volume of two layer compound cylinders [2]. Humid Jahed et al. have investigated the optimum design of a three-layered vessel for maximum fatigue life expectancy under the combined effects of autofrettage and shrink fit [3].

It is also assumed that the compound cylinder is fabricated by shrinking on each successive shell from the inside outwards and that after each shell is shrunk on, the outside diameter is machined to size before the next cylinder is shrunk-on to the inner shell or shells. In this paper three cylinders are considered. Cylinder 2 is shrink-fitted on cylinders 1 and cylinder 3 is shrink-fitted on cylinders 2 . The stress distribution is influenced by shrinking radii (the outer radii of the inner cylinders and the inner radii of the outer cylinders) and shrinking allowances (shrink fit). The main objective of the work is to optimize the values of these parameters so that the minimum material volume for the three layer compound cylinder is achieved while maximum tensile stresses in all three cylinders are equal.

\section{Lame's Theory}

The method of solution for compound cylinders constructed from similar materials is to break the problem down into four separate effects:

i) shrinkage pressure $P_{s 12}$ only on the cylinder 1

ii) shrinkage pressure $P_{s 12}$ and $P_{s 23}$ only on the cylinder 2

iii) shrinkage pressure $P_{s 23}$ only on the cylinder 3

iv) internal pressure $P_{i}$ only on the complete cylinder

2.1 Radial and Hoop stress in Cylinder 1

If $P_{i}=0$ i.e. with no internal pressure, radial stress in cylinder 1 is given by using Lame's equation: 


$$
\sigma_{r}=-P_{s 12} \frac{r_{2}^{2}}{r_{2}^{2}-r_{1}^{2}}\left(1-\frac{r_{1}^{2}}{r^{2}}\right)
$$

$\sigma_{r}$ is maximum at outer radius $r_{2}$ of cylinder 1 . Using equation (1):

$$
\sigma_{r \max \left(a t r_{2}\right)}=-P_{s 12}
$$

Hoop stress in cylinder 1 is given by using Lame's equation:

$$
\sigma_{\theta}=-P_{s 12} \frac{r_{2}^{2}}{r_{2}^{2}-r_{1}^{2}}\left(1+\frac{r_{1}^{2}}{r^{2}}\right)
$$

Hoop stress at outer radius $r_{2}$ is:

$$
\sigma_{\theta\left(a t r_{2}\right)}=-P_{s 12}\left[\frac{r_{2}^{2}+r_{1}^{2}}{r_{2}^{2}-r_{1}^{2}}\right]
$$

While hoop stress at inner radius $r_{1}$ is:

$$
\sigma_{\theta \max \left(a t r_{1}\right)}=-\left[\frac{2 P_{s 12} r_{2}^{2}}{r_{2}^{2}-r_{1}^{2}}\right]
$$

In the shrink-fitting problems, considering long hollow cylinders, the plane strain hypothesis (in general $\sigma_{z} \neq 0$ ) can be regarded as more natural. Hence as per relation:

$$
\sigma_{z}=v\left(\sigma_{r}+\sigma_{\theta}\right)
$$

the expression for the hoop strain is given by:

$$
\varepsilon_{\theta}=\frac{1}{E}\left[\sigma_{\theta}-v \sigma_{r}-v \sigma_{z}\right]=\frac{1}{E}\left[\sigma_{\theta}-v \sigma_{r}-v^{2}\left(\sigma_{r}+\sigma_{\theta}\right)\right]=\frac{1+v}{E}\left[(1-v) \sigma_{\theta}-v \sigma_{r}\right]
$$

Using equations (2) and (4), assuming plane strain condition the hoop strain at the outer wall $r_{2}$ of cylinder 1 is:

$$
\varepsilon_{\theta 1 o}=\frac{1+v}{E}\left[(1-v) \sigma_{\theta}-v \sigma_{r}\right]=\frac{1+v}{E}\left[(1-v)\left(-P_{s 12}\left[\frac{r_{2}^{2}+r_{1}^{2}}{r_{2}{ }^{2}-r_{1}^{2}}\right]\right)-v\left(-P_{s 12}\right)\right]=\frac{U_{r l o}}{r_{2}}
$$

Radial displacement $U_{r 1 o}$ is:

$$
U_{r 1 o}=\frac{-P_{s 12} r_{2}(1+v)}{E}\left[\left(-P_{s 12}\left[\frac{r_{2}^{2}+r_{1}^{2}}{r_{2}^{2}-r_{1}^{2}}\right]\right)-v\right]
$$

2.2 Radial and Hoop stress in Cylinder 2

Contact pressure $P_{s 12}$ is acting as internal pressure and contact pressure $P_{s 23}$ is acting as external pressure on cylinder 2.

Using Lame's equation, radial stress in the cylinder 2 at inner radius $r_{2}$ is given by:

$$
\sigma_{r\left(a t r_{2}\right)}=-P_{s 12}
$$

While radial stress in the cylinder 2 at outer radius $r_{3}$ is given by:

$$
\sigma_{r\left(a t r_{3}\right)}=-P_{s 23}
$$

Hoop stress in the cylinder 2 at inner radius $r_{2}$ is given by:

$$
\sigma_{\theta \max \left(a t r_{2}\right)}=P_{s 12}\left[\frac{r_{3}^{2}+r_{2}^{2}}{r_{3}^{2}-r_{2}^{2}}\right]-\left[\frac{2 P_{s 23} r_{3}^{2}}{r_{3}^{2}-r_{2}^{2}}\right]
$$

While hoop stress in the cylinder 2 at outer radius $r_{3}$ is given by:

$$
\sigma_{\theta\left(a t r_{3}\right)}=\left[\frac{2 P_{s 12} r_{2}^{2}}{r_{3}^{2}-r_{2}^{2}}\right]-P_{s 23}\left[\frac{r_{3}^{2}+r_{2}^{2}}{r_{3}^{2}-r_{2}^{2}}\right]
$$

Using equations (8) and (10), and assuming plane strain condition the hoop strain at the inner wall $r_{2}$ of cylinder 2 is:

$$
\begin{aligned}
\varepsilon_{\theta 2 i}=\frac{1+v}{E}\left[(1-v) \sigma_{\theta}-v \sigma_{r}\right]= & \\
& \frac{1+v}{E}\left[(1-v)\left(\left[P_{s 12} \frac{r_{3}^{2}+r_{2}^{2}}{r_{3}^{2}-r_{2}^{2}}-\frac{2 P_{s 23} r_{3}^{2}}{r_{3}^{2}-r_{2}^{2}}\right]\right)-v\left(-P_{s 12}\right)\right]=\frac{U_{r 2 i}}{r_{2}}
\end{aligned}
$$

Radial displacement $U_{r 2 i}$ : 


$$
U_{r 2 i}=\frac{r_{2}(1+v)}{E}\left[P_{s 12}\left((1-v) \frac{r_{3}^{2}+r_{2}^{2}}{r_{3}^{2}-r_{2}^{2}}+v\right)-(1-v)\left(\frac{2 P_{s 23} r_{3}^{2}}{r_{3}^{2}-r_{2}^{2}}\right)\right]
$$

Referring figure 3 and using equations (7) and (13), total interference $\delta_{12}$ at the contact between cylinder 1 and 2 is:

$$
\begin{aligned}
& \delta_{12}=U_{r 2 i}-U_{r 1 o} \\
& =\frac{r_{2}(1+v)}{E}\left[P_{s 12}\left((1-v) \frac{r_{3}^{2}+r_{2}^{2}}{r_{3}^{2}-r_{2}^{2}}+v\right)-(1-v)\left(\frac{2 P_{s 23} r_{3}^{2}}{r_{3}^{2}-r_{2}^{2}}\right)\right]-\frac{-P_{s 12} r_{2}(1+v)}{E}\left[\left(-P_{s 12}\left[\frac{r_{2}^{2}+r_{1}^{2}}{r_{2}^{2}-r_{1}^{2}}\right]\right)-v\right] \\
& =\frac{r_{2}(1-v)}{E}\left[P_{s 12}\left(\frac{r_{3}^{2}+r_{2}^{2}}{r_{3}^{2}-r_{2}^{2}}+\frac{r_{2}^{2}+r_{1}^{2}}{r_{2}^{2}-r_{1}^{2}}\right)-2 P_{s 23}\left(\frac{r_{3}^{2}}{r_{3}^{2}-r_{2}^{2}}\right)\right]
\end{aligned}
$$

Using equations (9) and (11), hoop strain in the outer wall $r_{3}$ of cylinder 2 is given by:

$$
\varepsilon_{\theta 2 o}=\frac{1+v}{E}\left[(1-v) \sigma_{\theta}-v \sigma_{r}\right]=\frac{1+v}{E}\left[(1-v)\left(\frac{2 P_{s 12} r_{2}^{2}}{r_{3}^{2}-r_{2}{ }^{2}}-\frac{P_{s 23}\left(r_{3}{ }^{2}+r_{2}^{2}\right)}{r_{3}{ }^{2}-r_{2}{ }^{2}}\right)-v\left(-P_{s 23}\right)\right]=\frac{U_{r 2 o}}{r_{3}}
$$

Hence radial displacement $U_{r 2 o}$ :

$$
U_{r 2 o}=\frac{r_{3}}{E}\left[\frac{2 P_{s 12} r_{2}^{2}\left(1-v^{2}\right)}{r_{3}^{2}-r_{2}^{2}}-P_{s 23}(1+v)\left((1-v) \frac{r_{3}^{2}+r_{2}^{2}}{r_{3}^{2}-r_{2}^{2}}-v\right)\right]
$$

\subsection{Radial and Hoop stress in Cylinder 3}

Contact pressure $P_{s 23}$ is acting as internal pressure on cylinder 3 and external pressure $P_{o}$ is zero.

Radial stress in the cylinder 3 at inner radius $r_{3}$ is given by:

$$
\sigma_{r\left(a r_{3}\right)}=-P_{s 23}
$$

Hoop stress in the cylinder 3 at inner radius $r_{3}$ is given by:

$$
\sigma_{\theta \max \left(a t r_{3}\right)}=P_{s 23}\left[\frac{r_{4}^{2}+r_{3}^{2}}{r_{4}^{2}-r_{3}^{2}}\right]
$$

While hoop stress in the cylinder 3 at outer radius $r_{4}$ is given by:

$$
\sigma_{\theta\left(a t r_{4}\right)}=\frac{2 P_{s 23} r_{3}^{2}}{r_{4}^{2}-r_{3}^{2}}
$$

Using equations (17) and (18), hoop strain at inner wall $r_{3}$ of cylinder 3 is given by:

$$
\varepsilon_{\theta 3 i}=\frac{1+v}{E}\left[(1-v) \sigma_{\theta}-v \sigma_{r}\right]=\frac{1+v}{E}\left[(1-v)\left(-P_{s 23}\left[\frac{r_{4}^{2}+r_{3}^{2}}{r_{4}^{2}-r_{3}^{2}}\right]\right)-v\left(-P_{s 23}\right)\right]=\frac{U_{r 3 i}}{r_{2}}
$$

Radial displacement $U_{r 3 i}$ :

$$
U_{r 3 i}=\frac{P_{s 23} r_{3}(1+v)}{E}\left[(1-v)\left(\frac{r_{4}^{2}+r_{3}^{2}}{r_{4}^{2}-r_{3}^{2}}\right)+v\right]
$$

Using equations (16) and (21), total interference $\delta_{23}$ at the contact between cylinder 2 and 3:

$$
\begin{aligned}
& \delta_{23}=U_{r 3 i}-U_{r 2 o} \\
& =\frac{P_{s 23} r_{3}(1+v)}{E}\left[(1-v)\left(\frac{r_{4}^{2}+r_{3}^{2}}{r_{4}^{2}-r_{3}^{2}}\right)+v\right]-\frac{r_{3}}{E}\left[\frac{2 P_{s 12} r_{2}^{2}\left(1-v^{2}\right)}{r_{3}^{2}-r_{2}^{2}}-P_{s 23}(1+v)\left((1-v) \frac{r_{3}^{2}+r_{2}^{2}}{r_{3}^{2}-r_{2}^{2}}-v\right)\right] \\
& =\frac{r_{3}(1-v)}{E}\left[P_{s 23}\left(\frac{r_{4}^{2}+r_{3}^{2}}{r_{4}^{2}-r_{3}^{2}}+\frac{r_{3}^{2}+r_{2}^{2}}{r_{3}^{2}-r_{2}^{2}}\right)-2 P_{s 12}\left(\frac{r_{2}^{2}}{r_{3}^{2}-r_{2}^{2}}\right)\right]
\end{aligned}
$$

Hoop stress at any radius $r$ in compound cylinder due to internal pressure only is given by:

$$
\sigma_{\theta}=P_{i} \frac{r_{1}^{2}}{r_{4}^{2}-r_{1}^{2}}\left(1+\frac{r_{4}^{2}}{r^{2}}\right)
$$

\section{Principle of superposition}

After finding hoop stresses at all the radii, the principle of superposition is applied, i.e. the various stresses are then combined algebraically to produce the resultant hoop stresses in the compound cylinder subjected to both shrinkage pressures and internal pressure $P_{i}$.

\subsubsection{Resultant hoop stress in cylinder 1}


Using equations (23) and (5), maximum hoop stress at the inner surfaces of cylinder 1 at $r_{1}$ :

$$
\sigma_{\theta 1}=P_{i}\left[\frac{r_{4}^{2}+r_{1}^{2}}{r_{4}^{2}-r_{1}^{2}}\right]-2 P_{s 12}\left[\frac{r_{2}^{2}}{r_{2}^{2}-r_{1}^{2}}\right]
$$

2.4.2 Resultant hoop stress in cylinder 2

Using equations (23) and (10), maximum hoop stress at the inner surfaces of cylinder 2 at $r_{2}$ :

$$
\sigma_{\theta 2}=\frac{P_{i} r_{1}^{2}}{r_{2}^{2}}\left[\frac{r_{4}^{2}+r_{2}^{2}}{r_{4}^{2}-r_{1}^{2}}\right]+\frac{P_{s 12}\left(r_{3}^{2}+r_{2}^{2}\right)-2 P_{s 23} r_{3}^{2}}{r_{3}^{2}+r_{2}^{2}}
$$

\subsubsection{Resultant hoop stress in cylinder 3}

Using equations (18) and (23), maximum hoop stress at the inner surfaces of cylinder 3 at $r_{3}$ :

$$
\sigma_{\theta 3}=\frac{P_{i} r_{1}^{2}}{r_{3}^{2}}\left[\frac{r_{4}^{2}+r_{3}^{2}}{r_{4}^{2}-r_{1}^{2}}\right]+P_{s 23}\left[\frac{r_{4}^{2}+r_{3}^{2}}{r_{4}^{2}-r_{3}^{2}}\right]
$$

\section{Optimum Design Based On Maximum Tensile Stress}

To obtain optimum values of the contact (shrinkage) pressures $P_{s 12}$ and $P_{s 23}$ which will produce equal hoop (tensile) stresses in all the three cylinders, maximum hoop stresses given by the equations (24), (25) and (26) have been equated.

Equating equations (24) and (25) i.e. $\sigma_{\theta 1}=\sigma_{\theta 2}$ and rearranging:

$$
\begin{array}{r}
P_{i}\left[\frac{r_{4}^{2}+r_{1}^{2}}{r_{4}^{2}-r_{1}^{2}}\right]-2 P_{s 12}\left[\frac{r_{2}^{2}}{r_{2}^{2}-r_{1}^{2}}\right]=\frac{P_{i} r_{1}^{2}}{r_{2}^{2}}\left[\frac{r_{4}^{2}+r_{2}^{2}}{r_{4}^{2}-r_{1}^{2}}\right]+\frac{P_{s 12}\left(r_{3}^{2}+r_{2}^{2}\right)-2 P_{s 23} r_{3}^{2}}{r_{3}^{2}+r_{2}^{2}} \\
\Rightarrow P_{s 12}\left[\frac{2 r_{2}^{2}}{r_{2}^{2}-r_{1}^{2}}+\frac{r_{3}^{2}+r_{2}^{2}}{r_{3}^{2}-r_{2}^{2}}\right]=P_{i}\left[\frac{r_{4}^{2}+r_{1}^{2}}{r_{4}^{2}-r_{1}^{2}}-\frac{r_{1}^{2}}{r_{2}^{2}}\left[\frac{r_{4}^{2}+r_{1}^{2}}{r_{4}^{2}-r_{1}^{2}}\right]\right]+P_{s 23} \frac{2 r_{3}^{2}}{r_{3}^{2}-r_{2}^{2}}
\end{array}
$$

Let the ratios: $t_{1}=\frac{r_{2}}{r_{1}}, t_{2}=\frac{r_{3}}{r_{2}}, t_{3}=\frac{r_{4}}{r_{3}}$

Let:

$$
\begin{aligned}
& k_{1}=2 \frac{r_{2}^{2}}{r_{2}^{2}-r_{1}^{2}}+\frac{r_{4}^{2}+r_{1}^{2}}{r_{4}^{2}-r_{1}^{2}}=\frac{2 t_{1}^{2}}{t_{1}^{2}-1}+\frac{t_{2}^{2}+1}{t_{2}^{2}-1} \\
& k_{2}=\frac{r_{4}^{2}+r_{1}^{2}}{r_{4}^{2}-r_{1}^{2}}-\frac{r_{1}^{2}}{r_{2}^{2}}\left[\frac{r_{4}^{2}+r_{2}^{2}}{r_{4}^{2}-r_{1}^{2}}\right]=\frac{t_{1}^{2} t_{2}^{2} t_{3}^{2}+1}{t_{1}^{2} t_{2}^{2} t_{3}^{2}-1}-\frac{t_{2}^{2} t_{3}^{2}+1}{t_{1}^{2} t_{2}^{2} t_{3}^{2}-1} \\
& k_{3}=2 \frac{r_{3}^{2}}{r_{3}^{2}-r_{2}^{2}}=\frac{2 t_{2}^{2}}{t_{2}^{2}-1}
\end{aligned}
$$

Hence equation (27) becomes:

$$
P_{s 12}=P_{i}\left[\frac{k_{2}}{k_{1}}\right]+P_{s 23}\left[\frac{k_{3}}{k_{1}}\right]
$$

Equating equations (25) and (26) i.e. $\sigma_{\theta 2}=\sigma_{\theta 3}$ and rearranging we get:

$$
\begin{aligned}
& \frac{P_{i} r_{1}^{2}}{r_{2}^{2}}\left[\frac{r_{4}^{2}+r_{2}^{2}}{r_{4}^{2}-r_{1}^{2}}\right]+\frac{P_{s 12}\left(r_{3}^{2}+r_{2}^{2}\right)-2 P_{s 23} r_{3}^{2}}{r_{3}^{2}+r_{2}^{2}}=\frac{P_{i} r_{1}^{2}}{r_{3}^{2}}\left[\frac{r_{4}^{2}+r_{3}^{2}}{r_{4}^{2}-r_{1}^{2}}\right]+P_{s 23}\left[\frac{r_{4}^{2}+r_{3}^{2}}{r_{4}^{2}-r_{3}^{2}}\right] \\
& \therefore P_{s 12} \frac{r_{3}^{2}+r_{2}^{2}}{r_{3}^{2}-r_{2}^{2}}=P_{i}\left[\frac{r_{1}^{2}}{r_{3}^{2}} \frac{r_{4}^{2}+r_{3}^{2}}{r_{4}^{2}-r_{1}^{2}}-\frac{r_{1}^{2}}{r_{2}^{2}} \frac{r_{4}^{2}+r_{2}^{2}}{r_{4}^{2}-r_{1}^{2}}\right]+P_{s 23}\left[\frac{r_{4}^{2}+r_{3}^{2}}{r_{4}^{2}-r_{3}^{2}}+\frac{2 r_{3}^{2}}{r_{3}^{2}-r_{2}^{2}}\right]
\end{aligned}
$$

Let: $\quad k_{4}=\frac{r_{4}^{2}+r_{2}^{2}}{r_{4}^{2}-r_{1}^{2}}=\frac{t_{2}^{2}+1}{t_{2}^{2}-1}$

$$
\begin{aligned}
& k_{5}=\frac{r_{1}^{2}}{r_{3}^{2}}\left[\frac{r_{4}^{2}+r_{2}^{2}}{r_{4}^{2}-r_{1}^{2}}\right]-\frac{r_{1}^{2}}{r_{2}^{2}}\left[\frac{r_{4}^{2}+r_{2}^{2}}{r_{4}^{2}-r_{1}^{2}}\right]=\frac{t_{3}^{2}+1}{t_{1}^{2} t_{2}^{2} t_{3}^{2}-1}-\frac{t_{2}^{2} t_{3}^{2}+1}{t_{1}^{2} t_{2}^{2} t_{3}^{2}-1} \\
& k_{6}=2 \frac{r_{3}^{2}}{r_{3}^{2}-r_{2}^{2}}+\frac{r_{4}^{2}+r_{3}^{2}}{r_{4}^{2}-r_{3}^{2}}=\frac{2 t_{2}^{2}}{t_{2}^{2}-1}+\frac{t_{3}^{2}+1}{t_{3}^{2}-1}
\end{aligned}
$$

Hence equation (33) becomes: 


$$
P_{s 12}=P_{i}\left[\frac{k_{5}}{k_{4}}\right]+P_{s 23}\left[\frac{k_{6}}{k_{4}}\right]
$$

Equations (11) and (15) have been solved to get $P_{s 12}$ and $P_{s 23}$ in terms of $P_{i}$ as follows:

$$
\begin{aligned}
& P_{s 12}=P_{i}\left[\frac{\left(k_{5} / k_{6}\right)-\left(k_{2} / k_{3}\right)}{\left(k_{4} / k_{6}\right)-\left(k_{1} / k_{3}\right)}\right] \\
& P_{s 23}=P_{i}\left[\frac{\left(k_{5} / k_{4}\right)-\left(k_{2} / k_{1}\right)}{\left(k_{3} / k_{1}\right)-\left(k_{6} / k_{4}\right)}\right]
\end{aligned}
$$

Putting the values of $t_{1}, t_{2}$ and $t_{3}$, the equations (14) and (22) can be written as:

$$
\begin{aligned}
& \delta_{12}=\frac{r_{2}\left(1-v^{2}\right)}{E}\left[P_{s 12}\left(\frac{t_{2}{ }^{2}+1}{t_{2}{ }^{2}-1}+\frac{t_{1}{ }^{2}+1}{t_{1}{ }^{2}-1}\right)-2 P_{s 23}\left(\frac{t_{2}{ }^{2}}{t_{1}{ }^{2}-1}\right)\right] \\
& \delta_{23}=\frac{r_{3}\left(1-v^{2}\right)}{E}\left[P_{s 23}\left(\frac{t_{3}^{2}+1}{t_{3}^{2}-1}+\frac{t_{2}^{2}+1}{t_{2}{ }^{2}-1}\right)-\frac{2 P_{s 12}}{t_{2}^{2}-1}\right]
\end{aligned}
$$

3.1 Steps in optimum design

1. Assume internal diameter of cylinder $1\left(d_{1}\right)$ say $100 \mathrm{~mm}$

2. Let the ratios $t_{1}=\frac{r_{2}}{r_{1}}, t_{2}=\frac{r_{3}}{r_{2}}, t_{3}=\frac{r_{4}}{r_{3}}$

3. For the given internal pressure $P_{i}$, one can find contact (shrinkage) pressures $P_{s 12}$ and $P_{s 23}$ in terms of ratios $t_{1}, t_{2}$ and $t_{3}$ using equations (33) and (34).

4. Find the volume of the compound cylinder using equation $V=\pi\left(d_{4}^{2}-d_{1}^{2}\right) / 4$

5. Minimize the volume subjected to the constraints, a) $\sigma_{\theta 1} \leq \sigma_{y}$, b) $\sigma_{\theta 2} \leq \sigma_{y}$, c) $\sigma_{\theta 3} \leq \sigma_{y}$, d) $\delta_{12}>0$ and e) $\delta_{23}>0$,

6. Optimize parameters $t_{1}, t_{2}, t_{3}$ and $\delta_{12}, \delta_{23}$.

7. By selecting the various values of $t_{1}, t_{2}$ and $t_{3}$ and using iterative numerical method (with the help of computer programming), contact (shrinkage) pressures $P_{s 12}$ and $P_{s 23}$ for given internal pressure $P_{i}$ are calculated using equations (38) and (39) respectively. These contact pressures are then used to find out interferences $\delta_{12}, \delta_{23}$ with the help of equations (40) and (41) respectively. Volume is minimized subjected to the above said constraints. Actually the condition that maximum hoop stresses in all three cylinders being equal is met by number of combinations of $t_{1}, t_{2}$ and $t_{3}$. Out of these, some selected combinations have been included in this paper where volume is relatively less as compared to rest of the combinations. Using the five selected combinations of $\mathrm{t}_{1}, \mathrm{t}_{2}, \mathrm{t}_{3}, \mathrm{~d}_{2}, \mathrm{~d}_{3}, \mathrm{~d}_{4}, \delta_{12}$ and $\delta_{23}$ are calculated through computer programming and results are listed in the table no. 1. It is found that parameters in set no. 5 produce minimum volume.

Analytical Results of (MS-EXCEL):

Table no. 1

\begin{tabular}{|c|c|c|c|c|c|}
\hline Parameters & Set 1 & Set 2 & Set 3 & Set 4 & Set 5 \\
\hline$t_{1}$ & 1.17 & 1.3 & 1.22 & 1.38 & 1.20 \\
\hline$t_{2}$ & 1.35 & 1.2 & 1.3 & 1.3 & 1.29 \\
\hline$t_{3}$ & 1.44 & 1.44 & 1.45 & 1.27 & 1.45 \\
\hline$d_{2}$ & 117 & 130 & 122 & 138 & 120 \\
\hline$d_{3}$ & 157.95 & 156 & 158.6 & 179.4 & 154.8 \\
\hline$d_{4}$ & 227.44 & 224.64 & 229.97 & 227.83 & 224.46 \\
\hline$\sigma_{\theta 1 \text { max }}$ & 246.58 & 249.718 & 241.017 & 241.714 & 249.72 \\
\hline Parameters & Set 1 & Set 2 & Set 3 & Set 4 & Set 5 \\
\hline
\end{tabular}


Optimum Design of Three Layer Compound Cylinder

\begin{tabular}{|c|c|c|c|c|c|}
\hline$\sigma_{\theta 2 \text { max }}$ & 246.58 & 249.718 & 241.017 & 241.714 & 249.94 \\
\hline$\sigma_{\theta 3 \text { max }}$ & 246.58 & 249.718 & 241.017 & 241.714 & 249.94 \\
\hline$\sigma_{\theta 1 \text { min }}$ & -123.225 & -123.851 & -125 & -127.589 & -126.363 \\
\hline$\sigma_{\theta 2 \text { min }}$ & -39.709 & 3.445 & -24.407 & 19.464 & 19.943 \\
\hline$\sigma_{\theta 3 \text { min }}$ & 62.461 & 59.817 & 60.161 & 85.84 & 86.528 \\
\hline$\delta_{12}$ & 0.0186 & 0.0315 & 0.0234 & 0.0383 & 0.038 \\
\hline$\delta_{23}$ & 0.0364 & 0.0225 & 0.0316 & 0.0326 & 0.032 \\
\hline$p_{s 12}$ & 16.603 & 25.283 & 20.602 & 30.295 & 29.5 \\
\hline$p_{s 23}$ & 21.581 & 20.893 & 23.246 & 22.005 & 21.948 \\
\hline Volume & 32757.22 & 31763.55 & 33665.66 & 32909.95 & $\mathbf{3 1 7 6 3}$ \\
\hline
\end{tabular}

\subsection{Effects of parameters in design}

The effects of variation of $t_{1}, t_{2}$ and $t_{3}$ and the interferences on the maximum principal stresses in all three cylinders are shown in the following figures.

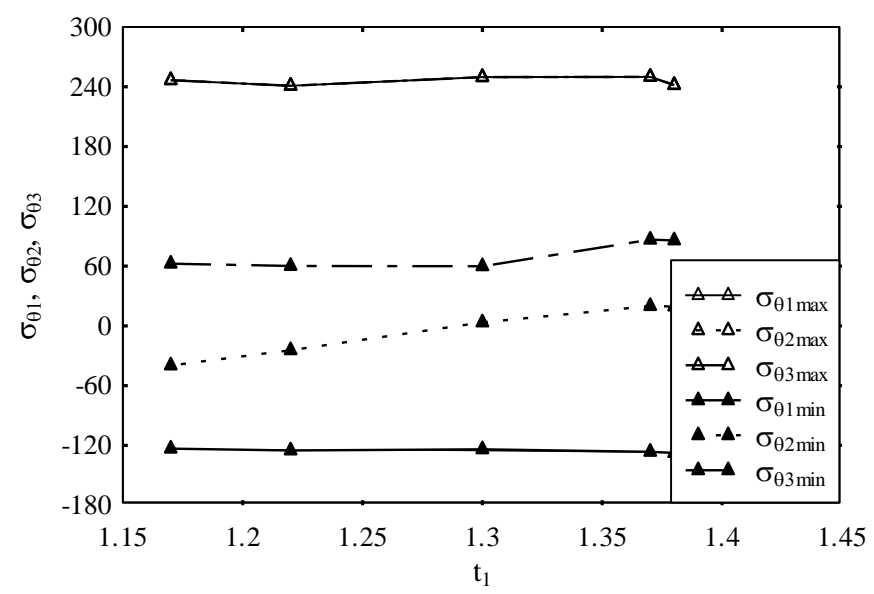

Fig 1: Variation of maximum and minimum hoop stresses w. r. t. $t_{1}$

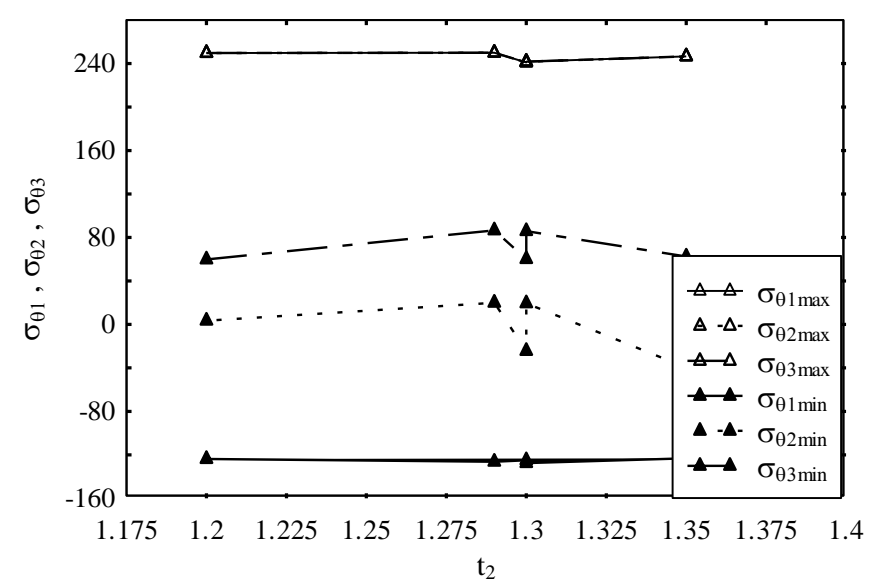

Fig 2: Variation of maximum and minimum hoop stresses w. r. t. $t_{2}$ 


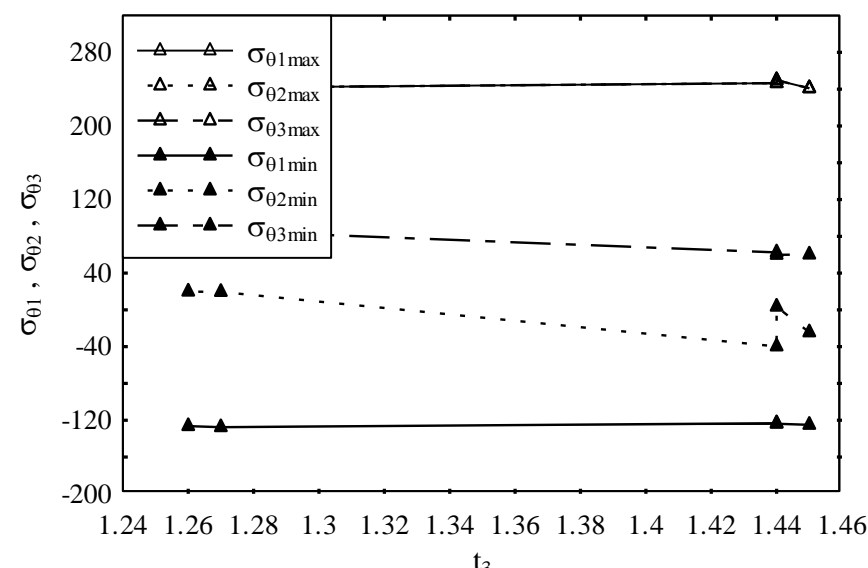

Fig 3: Variation of maximum and minimum hoop stresses w. r. t. $t_{3}$

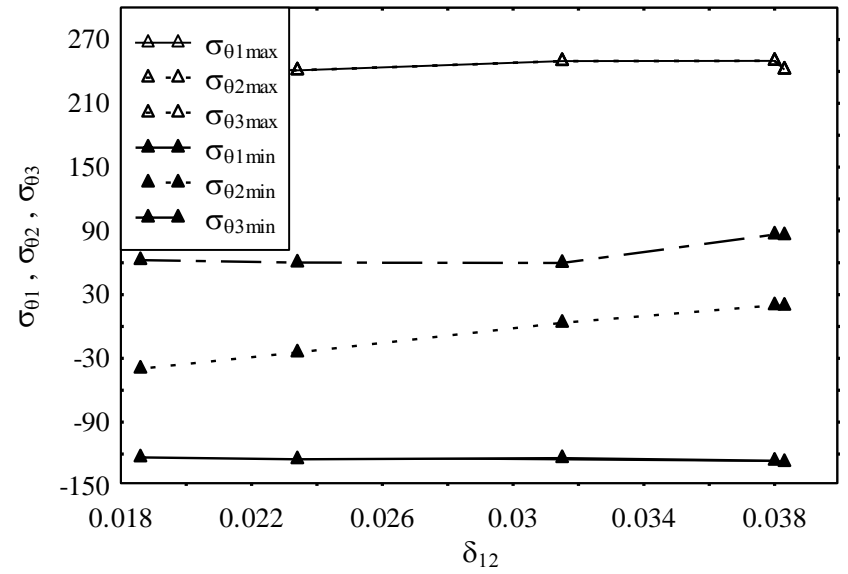

Fig 4: Variation of maximum and minimum hoop stresses w. r. t. $\delta_{12}$

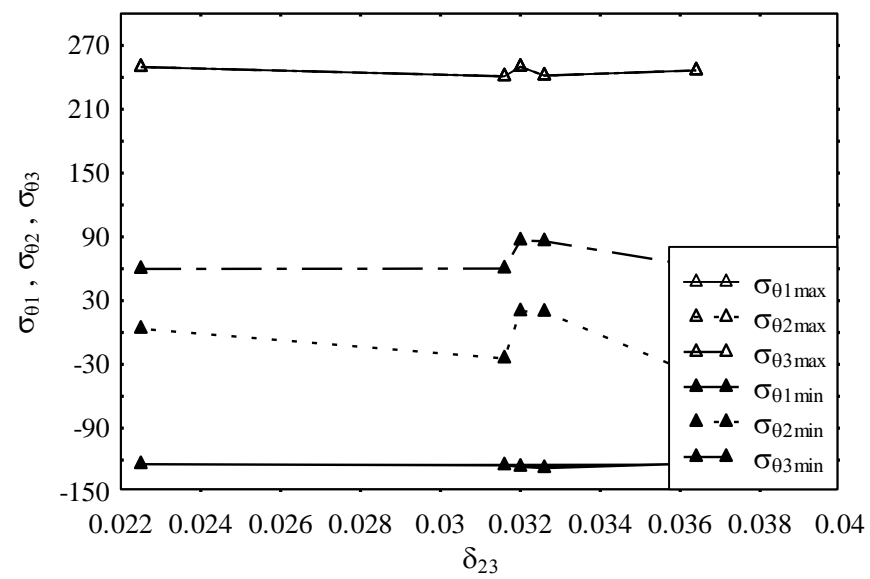

Fig 5: Variation of maximum and minimum hoop stresses w. r. t. $\delta_{23}$

From the Fig. 1, 2, 3, 4 and 5, it is observed that for change in $t_{1}, t_{2}, t_{3}, \delta_{12}$ and $\delta_{23}$ there is little difference in maximum principal stress at the inner surfaces in all three cylinders. Hence for minimum weight of three layer compound cylinder, the values of $t_{1}, t_{2}$ and $t_{3}$ are so chosen that it will keep the maximum hoop stresses developed in all three cylinders are equal. 


\section{Validation By FEM}

The three layer compound cylinder is modeled in design modeler of Ansys Workbench'13 with the computed dimensions. Here, we have used brick elements for meshing. The type of bond is coarse and mesh size is $10 \mathrm{~mm}$. The contact between these cylinders are rough-solid to solid contact. The inner surface of the cylinder is subjected to fluid pressure of $250 \mathrm{~N} / \mathrm{mm}^{2}$. To avoid rigid body motion, weak spring forces in appropriate directions are applied.

Data for modeling in Ansys:

Table no. 2

\begin{tabular}{|l|l|l|l|l|l|l|l|l|l|l|}
\hline$t_{1}$ & $t_{2}$ & $t_{3}$ & $d_{1}$ & $d_{2}$ & $d_{2 i}$ & $d_{3}$ & $d_{3 i}$ & $d_{4}$ & $\delta_{12}$ & $\delta_{23}$ \\
\hline 1.20 & 1.29 & 1.45 & 100 & 120 & 119.96 & 154.8 & 154.76 & 222.46 & .022 & .032 \\
\hline
\end{tabular}

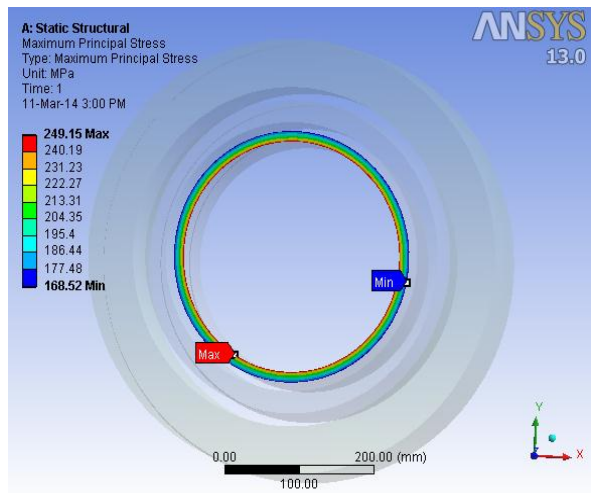

Fig 6: Maximum principal stress in cylider 1

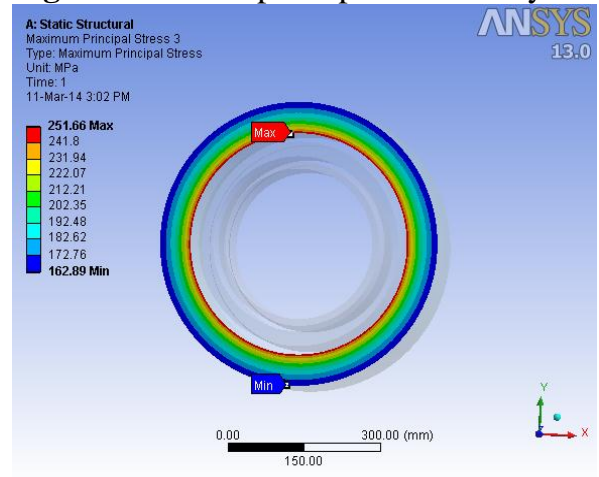

Fig 8: Maximum principal stress in cylider 3

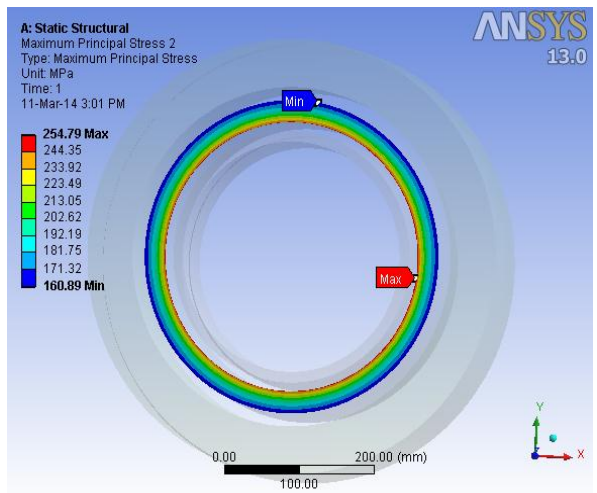

Fig 7: Maximum principal stress in cylider 2

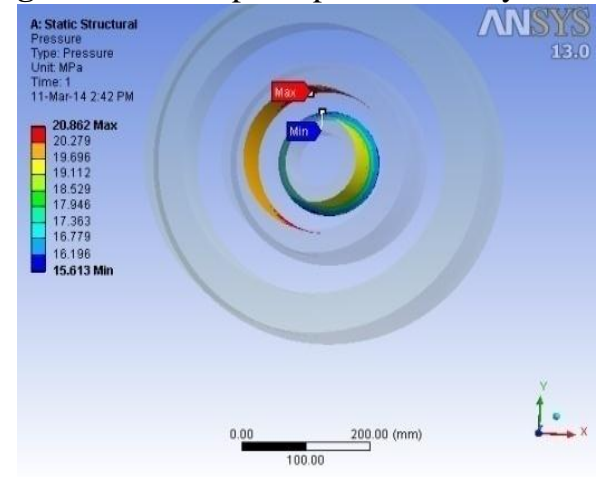

Fig 9: Contact pressure between cylinders no. $1 \& 2$ without $P_{i}$

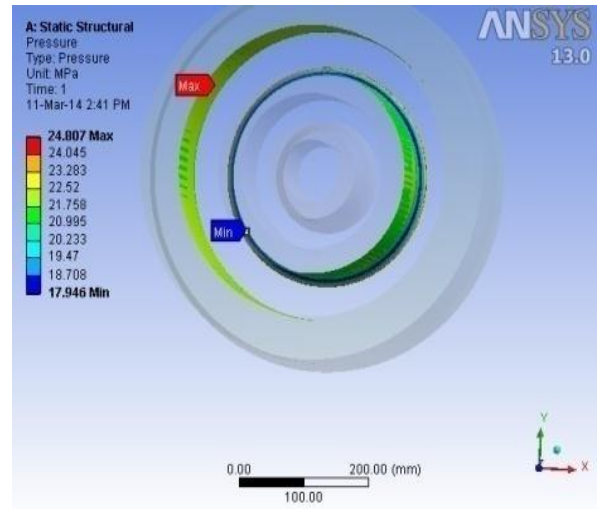

Fig 10: Contact pressure between cylinders no. $2 \& 3$ without $P_{i}$ 
FEM model of three layer compound cylinder is prepared in ANSYS Workbench'13 using values of the diameters from table no. 2 .

Table no. 3

\begin{tabular}{|l|c|c|c|}
\hline \multirow{2}{*}{ Parameter } & \multicolumn{3}{|c|}{ Maximum Hoop stress with pressure 250 MPa } \\
\cline { 2 - 4 } & Analytical results $(M P a)$ & FEM result $(M P a)$ & Error (\%) \\
\hline $1^{\text {st }}$ cylinder & 249.94 & 249.15 & 0.31 \\
\hline $2^{\text {nd }}$ cylinder & 249.94 & 254.79 & 1.94 \\
\hline $3^{\text {rd }}$ cylinder & 249.94 & 251.66 & 0.68 \\
\hline
\end{tabular}

Table no. 4

\begin{tabular}{|l|c|c|c|}
\hline \multirow{2}{*}{ Parameter } & \multicolumn{3}{|c|}{ Contact pressure without internal pressure } \\
\cline { 2 - 4 } & Analytical results $(M P a)$ & FEM results $(M P a)$ & Error (\%) \\
\hline$P_{s 12}$ & 18.922 & 20.862 & 10.2 \\
\hline$P_{s 23}$ & 20.893 & 24.807 & 18.73 \\
\hline
\end{tabular}

From the table no. 3 and 4 it is observed that there is very small difference in analytical and FEM results, i.e. FEM gave virtually similar results as analytical ones.

\section{Conclusion}

Multilayer compound cylinders are suitable for high operating pressures.

There is saving in material by using multilayered compound cylinder as compared to solid walled cylinder. This decreases not only weight of compound cylinder but also the cost of the material required to manufacture of multilayered compound cylinder.

$>\quad$ The results are indicated that for an optimum condition, the stress at the inner surfaces of all cylinders become equal to the yield stresses of the materials used for multilayer compound cylinders.

Theoretical calculated values by using different lame's formula are very close to that of values obtained from "ANSYS WORKBENCH'13" analysis. The differences are due to the numerical techniques.

\section{References:}

[1]. G.H. Majzoobi, A. Ghomi (2006) "Optimization of compound pressure cylinders", Journal of Achievements in Materials and Manufacturing Engineering, Vol. 15, Issue 1-2 March-April.

[2]. Patil Sunil A., (2011) "Finite Element Analysis of optimized compound cylinder", Journal of Mechanical Engineering Research, Vol. 3(1), Issue March.

[3]. Humid Jahed, Behrooz Farshi and Morvarid Karimi (2006) "Optimum Autofrettage \& Shrink-Fit Combination in Multi-Layer Cylinders", Journal of Pressure Vessel Technology, Transactions of the ASME, pp. 196-200, Vol. 128, MAY (2006).

[4]. A. A. Miraje, S. A. Patil (2011) "Minimization of material volume of three layer compound cylinder having same materials subjected to internal pressure”, International Journal of Engineering, Science and Technology, Vol. 3, No. 8, 2011, pp. 26-40.

[5]. Ayub A. Miraje and Dr. Sunil A. Patil (2011) "Infinite fatigue life of three layer shrink fitted compound cylinder under fluctuation internal pressure “,International Journal of Mechanical Engineering \& Technology (IJMET), Vol 3, Issue 1, Journal-April (2012), pp. 288-299. 